\title{
Interprofessional Geriatrics Education Program: Train the Trainer Pilot Model
}

\author{
Balogun SA ${ }^{1^{*}}$, Fletcher $\mathrm{K}^{2}$ and Bradley EB ${ }^{3}$ \\ ${ }^{1}$ Division of General Medicine, Geriatrics/Palliative Care, University of Virginia Health System, USA \\ ${ }^{2}$ Director Geriatric Nurse Clinical Practice Program Riverside Health System, University of Virginia, USA \\ ${ }^{3}$ University of Virginia School of Medicine, USA
}

"Corresponding author: Balogun SA, Department of Internal Medicine, Division of General Medicine, Geriatrics/Palliative Care, University of Virginia Health System P.O. Box 800901 Charlottesville, VA, USA, Tel: 434-2434849; Fax: 434-2439282; E-mail: sab2s@virginia.edu

Rec date: Apr 21, 2014; Acc date: Jun 23, 2014; Pub date: Jun 25, 2014

Copyright: (c) 2014 Balogun SA, et al. This is an open-access article distributed under the terms of the Creative Commons Attribution License, which permits unrestricted use, distribution, and reproduction in any medium, provided the original author and source are credited.

\begin{abstract}
Background: With the rapid aging of the U.S. population, the proportion of elderly adults far exceeds the capacity of geriatric trained health professionals for care. As a result of this critical shortage, health professionals without formal training in geriatrics, mostly provide care in the elderly. We developed and implemented an Interprofessional Geriatrics Education (IPGE) pilot program for non-geriatric trained clinical health professionals to foster enhanced knowledge and skills in geriatric care. In addition, we utilized a Train-The-Trainer (TTT) model in which participants will then disseminate these best practice principles to others.
\end{abstract}

Methods: As an initiative of the Virginia Geriatric Education Center, ten health professionals from four disciplines were enrolled in the 40-hour comprehensive, longitudinal educational program using both on line and in class format, with a focus on falls, geriatric syndromes, and transitions in geriatric care, pharmacotherapy and the development of a dissemination project. Participant feedback was through the online platform and exit interviews.

Results: One hundred percent of participants stated that the content met their educational needs, and $81 \%$ stated that they intend to make a practice change as a result of the program. On a 5-point Likert scale (poor=1, excellent=5), the participants rated the effectiveness of the teaching sessions (average: 4.6/5.0), the faculty (average: $4.7 / 5.0$ ), the presentations (4.4/5.0), the syllabi (average: 4.4/5.0), and the use of audio-visuals (average: 4.3/5.0). Overall, participants enhanced their knowledge of clinical geriatric care. They also developed proposals of dissemination projects.

Conclusion: IPGE can be a useful tool in improving geriatric care and provides a meaningful way to train practitioners from multiple disciplines at the same time, who then train others, in an effort to address the shortage in geriatric care providers.

Keywords: Interprofessional education; Geriatric education; Geriatric care

\section{Introduction}

With the rapid aging of the United States (US) population, the proportion of elderly adults far exceeds the capacity of geriatric trained specialists. As of 2003, there were only about 5.5 geriatricians per 10,000 patients, 75 years and older [1]. The trend in the number of physicians certified in geriatric medicine in the last 10 years has been relatively stagnant, if not on a decline [2]. This figure is just as small in other health professions. According to the 2013 American Nurses Credentialing Center Survey, there were only a little over 7000 nurses certified in gerontology [3]. In 2011, US adults age 65 years and above made up almost $13 \%$ of the total population and were over 39 million in number.With life expectancy increasing, this number is projected to double by the year 2040, when all 'baby boomers' will be at least 65 years of age [4]. Within the same time frame, the number of geriatricians currently just over 7000, is not expected to increase significantly given the falling entry rates of new doctors into the geriatric field [2]. This situation makes the geriatric work force shortage critical and dire. As a result of this shortage, many health professionals without formal training in geriatric care are currently providing care for the elderly. This creates suboptimal medical management of these patients as these health practitioners often times lack the appropriate knowledge of geriatric principles.

Inter-professional education, using expert faculty from various disciplines to teach health care professionals from these same disciplines, is one approach to maximize scarce expert resources. Having these health care professionals then disseminate this knowledge further magnifies this effect and can help to decrease the shortage of trained professionals. The Train-The-Trainer (TTT) model is a well-known educational tool and has been utilized in education programs for different medical disciplines including geriatrics; however none of these published programs have incorporated Interprofessional principles [5]. We developed and implemented an Interprofessional geriatrics education pilot program for non- geriatric trained health professionals involved in geriatric care in community clinical settings. The intent of the program is to foster enhanced knowledge and skills in geriatric care and have the participants disseminate geriatric best practice principles to others, using the TTT approach. 


\section{Methods}

The Virginia Geriatric Education Center, a consortium of healthrelated departments in three universities (Virginia Commonwealth University, University of Virginia, Eastern Virginia Medical School), with funding from Health Resources Services Administration (HRSA) in 2010 has established geriatric education programs across Virginia. One of the many initiatives of the center includes an interdisciplinary TTT pilot program, a forty -hour comprehensive geriatrics education program. The first TTT program was implemented in Central Virginia over a three-month period of time, in the spring of 2012 and included ten health professionals from four disciplines (community physicians, nursing, physical therapy and occupational therapy).

\begin{tabular}{|l|l|}
\hline Participants (N-10) & Number (\%) \\
\hline Profession & \\
\hline Medicine & $2(20 \%)$ \\
\hline Nursing & $4(40 \%)$ \\
\hline Occupational therapy & $2(20 \%)$ \\
\hline Physical therapy & $2(20 \%)$ \\
\hline Clinical site & \\
\hline Ambulatory/Home care & $8(80 \%)$ \\
\hline Hospital & 0 \\
\hline Long term care & $2(20 \%)$ \\
\hline Sex/Race & \\
\hline Female/Caucasian & $10(100 \%)$ \\
\hline Male & 0 \\
\hline
\end{tabular}

Table 1: Demography of participants

Participants were all volunteers and were not compensated for their time. Recruitment was done electronically through email and verbally through professional contacts of the faculty. Most of the participants $(80 \%)$ practice in the ambulatory/home care setting and they were all female and Caucasian (Table 1).

The program used a hybrid approach to content delivery, utilizing both on-site and online components. The 18 -hour $(45 \%$ of the total program time) on-site component of the program was delivered over 4 days during the 3 -month period. This consisted of 14 interactive workshop presentations by interprofessional faculty which included a geriatrician, several geriatric nurse practitioners, a geriatric certified physical therapist, a social worker with geriatric expertise, two experts in adult learning, and a program evaluation specialist (including authors SB, KF, EB). The focus of the workshops was common geriatric syndromes using falls as an exemplar, transitions in geriatric care, geriatric pharmacotherapy as well as content on the principles of adult learning and teaching strategies. In addition, participants were also instructed on how to design and develop an educational dissemination project.

The online component formed about $35 \%$ of the total program time (14 hours). It involved an interactive online platform where peer review articles related to the workshops were posted with a discussion forum [6-10], in which participants were expected to engage in dialogue by asking and responding to questions posed by faculty or other participants.

Participants spent $20 \%$ of the total program time ( 8 hours) in developing their dissemination project and at the end of the program; they presented the proposed project to their colleagues and the faculty. Participants evaluated the program online after each of the four full day sessions using a QuestionPro survey, which included questions about the overall effectiveness of the sessions and the speakers, the method of presentation, the opportunity to participate, the quality of the materials, the use of audiovisuals, session learning objectives (5point Likert scale, poor $=1$, excellent $=5$ ). Additionally participants were asked (yes/no) whether the session met their educational needs, if the level of difficulty of the presentation was appropriate, and whether the sessions spurred them to consider making a practice change. All participants also took part in a one-hour exit interview process administered by the program evaluation specialist (EB). Comments were recorded by hand, and summary results were developed. The questions in the exit interview focused on the specific content that was most useful in participants' daily work, what changes participants plan to make in daily practice as a result of the program, specific benefits of the program, barriers that prevented participants from taking full advantage of the program (if any), the greatest strength of the program, and areas for improvement.

\section{Results}

According to the exit interview results, all of the participants evaluated the core content of the program (geriatric syndromes, geriatric pharmacotherapy, and falls assessment) as useful and relevant in their daily work. One hundred percent of participants across all four full day sessions stated that both the online and in-class content met their educational needs. Eight one percent of participants stated that they intend to make a practice change as a result of their interaction with either the online or in class content. Additionally, on a 5-point Likert scale (poor $=1$, excellent $=5$ ), the participants rated the effectiveness of the teaching sessions (average: 4.6/5.0), the faculty (average: $4.7 / 5.0$ ), the presentations (average: 4.4/5.0), the syllabi (average: 4.4/5.0), and the use of audio-visuals (average: 4.3/5.0), with a range from 3.0-5.0. A summary of representative quotes from the exit interview are provided in Table 2.

The Interprofessional learning environment and interaction with professionals from multiple disciplines was favorably received. The participants also reported that the speakers, the variety of topics, and the interactive nature of the sessions were strengths of the program. They felt that the more interactive the program, the better, and that contingencies should be made when offering online course materials, as some rural areas may not have reliable internet access. All participants developed and presented a proposal of a dissemination project to educate other professionals in their respective fields. Dissemination projects include proposals on teaching home health therapists and aides the risks associated with transitions in geriatric care from the hospital to the home setting, teaching corporate leaders in long term care the role and function of the medical director, teaching nurses in the nursing home how to recognize, report and follow up on signs of sepsis, teaching home health aides proper skin care and teaching caregivers the risks/prevention of falls in the home. 
Citation: Balogun SA, Fletcher K, Bradley EB (2014) Interprofessional Geriatrics Education Program: Train the Trainer Pilot Model. J Gerontol Geriat Res 3: 161. doi:10.4172/2167-7182.1000161

Page 3 of 4

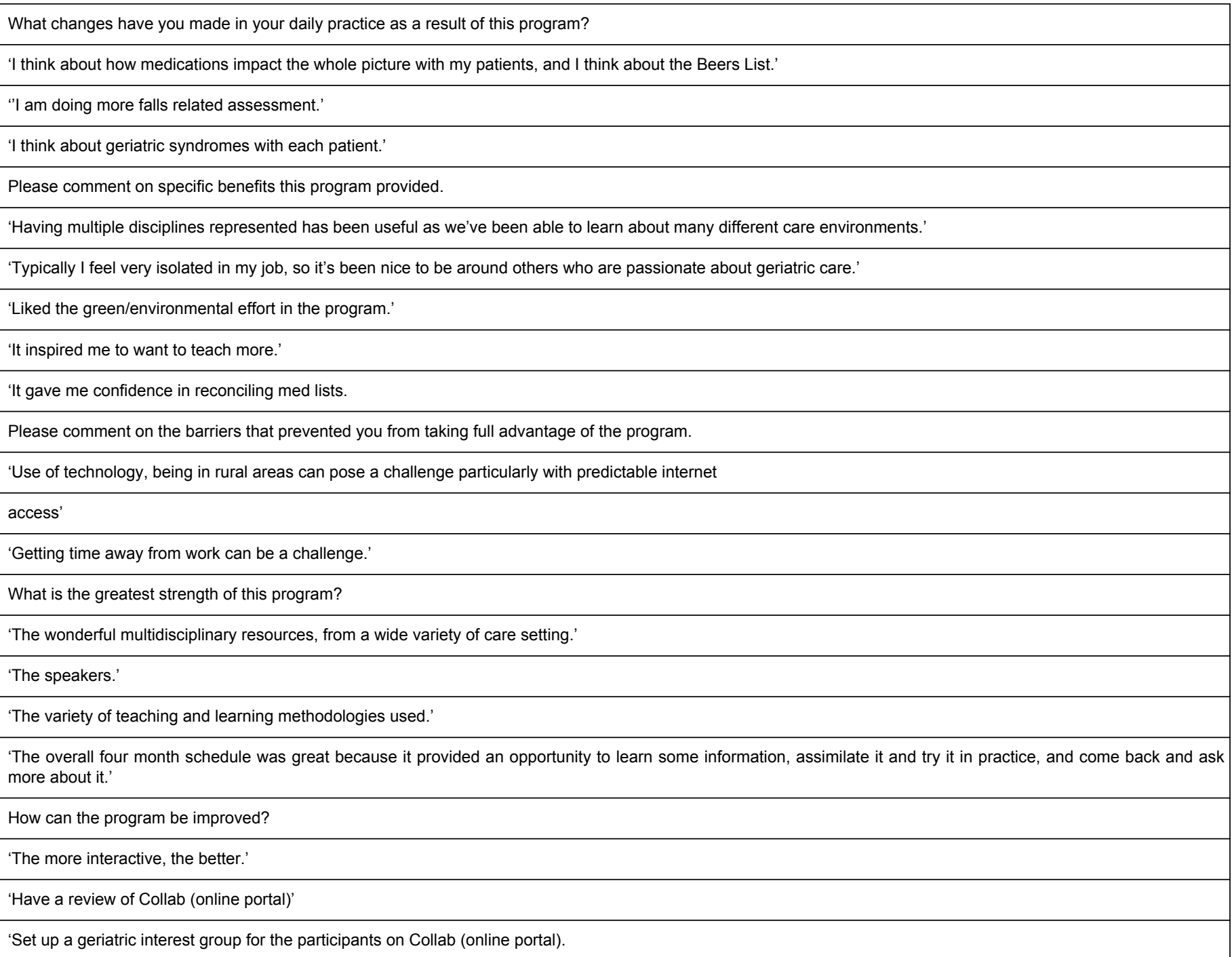

Table 2: Summary of representative quotes of participants on exit interview

\section{Discussion}

Interprofessional geriatric education (IPGE) can be a useful tool in improving geriatric care in the community. In our pilot, health professionals from four different disciplines, without formal geriatric training were able to enhance their knowledge of clinical geriatric care. In addition, these professionals would be able to implement changes in their clinical practice by teaching other practicing health care professionals in their respective communities to improve the quality of care delivered to older adults.

The limitations of this pilot program include the small number of participants, no randomization in recruitment and lack of racial diversity or diversity in clinical practice sites of participants. While these make it difficult to generalize these results, there have been other IPGE programs that have shown similar favorable results $[11,12]$.

However unlike our pilot study, none of the programs incorporated both Interprofessional principles and the TTT model, which has the potential to facilitate greater dissemination of knowledge of geriatric principles. To fully assess the impact of an IPGE program like ours, which utilizes the TTT model to improve the knowledge of health professionals and geriatric care, further investigation is warranted. This could focus on subsequent dissemination of the TTT content by the program participants in their workplace or practice settings.

\section{Next steps}

The Train the Trainer Program is being replicated in two other areas in Virginia using the hybrid approach of both on line and on site education. Recruitment of participants from diverse clinical sites of care (hospital, long term, ambulatory and home care) is a focus in order to provide a richer discussion about the challenges in care transitions across setting and encourage collaborative dissemination projects. 
Citation: Balogun SA, Fletcher K, Bradley EB (2014) Interprofessional Geriatrics Education Program: Train the Trainer Pilot Model. J Gerontol Geriat Res 3: 161. doi:10.4172/2167-7182.1000161

Page 4 of 4

\section{Acknowledgements}

All three authors contributed to the study concept and design, acquisition of data, analysis and interpretation of data, and preparation of manuscript.

Funding source: Virginia Geriatric Education Center Consortium Grant Funded by U.S. Health Resources and Services Administration.

Accepted for oral and poster presentation at American Geriatrics Society Annual Meeting- May 2013

\section{References}

1. Warshaw GA, Bragg EJ (2003) The training of geriatricians in the United States: three decades of progress J Am Geriatr Soc 51: S338-S345.

2. Warshaw GA, Bragg EJ, Brewer DE, Meganathan K, Ho M (2007) The development of academic geriatric medicine: progress toward preparing the nation's physicians to care for an aging population. J Am Geriatr Soc 55: 2075-2082.

3. American Nurses Credentialing Center (2013) Role Delineation Study: Gerontological Nursing National Survey Results.

4. United States Census Bureau (2011) The older population in the United States

5. Levine SA, Brett B, Robinson BE, Stratos GA, Lascher SM, et al. (2007) Practicing Physician Education in Geriatrics: Lessons Learned from a
Train-the-Trainer Model. Journal of the American Geriatrics Society 55: 1281-1286.

6. Boling P (2009) Care Transitions and Home Health Care. Clin Geriatr Med 25: 135-148

7. Inouye SK, Studenski S, Tinetti ME, George A Kuchel, Geriatric Syndromes : Clinical Research and Policy Implications of a Core Geriatric Concept. J American Geratrics Society 55: 780-791.

8. Rubenstein LZ (2004) Comprehensive Geriatric Assessment: From Miracle to Reality Journal of Gerontology: MEDICAL SCIENCES 59A: 473-477.

9. Lindguist LA, Baker DW (2011) Understanding Preventable Hospital Readmissions: Masqueraders, Markers, and True Causal Factors. Journal of Hospital Medicine 6: 51-53.

10. Delafuente JC (2008) Pharmacokinetic and Pharmacodynamic Alterations in the Geriatric Patient. The Consultant Pharmacist 23: 324-334

11. Toner JA, Ferguson KD, Sokal RD (2009) Continuing interprofessional education in geriatrics and gerontology in medically underserved areas. J Contin Educ Health Prof 29: 157-160.

12. Collins L, Arenson C, Jerpak C, Kane P, Dressel R, et al. (2011) Transforming chronic illness care education: A longitudinal interprofessional mentorship curriculum. Journal of Interprofessional Care 25: 228-230. 